\title{
A VIOLÊNCIA SIMBÓLICA CONTRA OS ALUNOS EM VULNERABILIDADE SOCIAL DURANTE A PANDEMIA
}

\section{SYMBOLIC VIOLENCE AGAINST STUDENTS IN SOCIAL VULNERABILITY DURING THE PANDEMIC}

\author{
Natercia de Andrade Lopes Neta ${ }^{1}$ \\ Universidade Estadual de Alagoas e SEMED Maceió, AL, Brasil \\ Ana Paula Mendes Correia Couceiro Figueira ${ }^{2}$ \\ Universidade de Coimbra, Portugal
}

\begin{abstract}
Resumo: A maior crise sanitária e humanitária do novo milênio agravou a vulnerabilidade social dos alunos da rede pública. Com fome, muitos pais tiveram que sair de suas casas para procurar trabalho e delegaram aos filhos a missão de cuidar da casa e dos afazeres domésticos, objetivando abordar as implicações desta realidade na vida escolar dos alunos, realizamos uma pesquisa explicativa com coleta de dados através de formulário eletrônico, e análise descritiva a partir das respostas de 55 estudantes voluntários da pesquisa, de 3 bairros com alto índice de vulnerabilidade social. Percebemos que, afastados da Escola, sem tempo e condições técnicas de assistir as aulas de forma remota, os alunos não percebem a violência simbólica por trás dos discursos que justificam a ausência de políticas públicas educacionais.

Palavras-chave: Coronavírus, Educação Básica, Políticas públicas, Vulnerabilidade social, Violência simbólica.

Abstract: The biggest health and humanitarian crisis of the new millennium has aggravated the social vulnerability of public school students. Hungry, many parents had to leave their homes to look for work and delegated to their children the mission of taking care of the house and household chores, aiming to approachar as a result of the reality in the students' school life, we conducted a dicative research through the collection of forms electronic, and descriptive analysis of the responses of 55 students subjects of the research, from 3 neighborhoods with a high level of social vulnerability. We realized that, away from the School, without the time and technical conditions to attend classes remotely, students do not perceive the symbolic violence behind the speeches that justify the absence of public educational policies.
\end{abstract}

Keywords: Coronavirus, Basic Education, Public policies, Social vulnerability, Symbolic violence

\section{Introdução}

$\mathrm{Na}$ primeira onda da pandemia, observamos em Maceió, o princípio de lockdown, alunos e pais em casa, fome, crise sanitária, violência, distanciamento da escola... Após alguns meses de sofrimento para as famílias em vulnerabilidade surge o auxílio emergencial repassado pelo governo federal, e a regressão no número de casos de Coronavírus. A flexibilização das

\footnotetext{
${ }^{1}$ Doutora em Ciências da Educação pela Universidade Federal de Pernambuco (UFPE), Professora Adjunta do Curso de Matemática da Universidade Estadual de Alagoas e do Ensino Fundamental na Prefeitura de Maceió. E-MAIL: natercia.lopes@uneal.edu.br. ORCID: http://orcid.org/0000-0002-5532-9300.

2 Doutora em psicologia pela Universidade de Coimbra, professora Auxiliar na Universidade de Coimbra-Faculdade de Psicologia e de Ciências da Educação. E-MAIL: apcouceiro@fpce.uc.pt.

Revista Tópicos Educacionais, Pernambuco, v. 27, n. 01, p. 22-33, 2021. ISSN: 2448-0215. https://periodicos.ufpe.br/revistas/topicoseducacionais/index Dossiê "Conflitos, violências, bullying na escola: problemas da convivência potencializado pela pandemia?" DOI: 10.51359/2448-0215.2021.250234
} 
medidas de restrição e reabertura do comércio favoreceram que os pais pudessem retornar aos seus postos de trabalho, porém, as escolas públicas continuaram fechadas. Em casas pequenas, com 1 quarto para 5 pessoas, os alunos se viram obrigados a cuidarem dos afazeres domésticos e de seus irmãos, sobrinhos, vizinhos, no horário das aulas.

A vulnerabilidade social presente no cotidiano destes alunos se agravou durante a pandemia, e a violência simbólica por trás dos discursos de que o governo já tinha feito de tudo para ajudar, resultou na ausência de políticas públicas voltadas para a Educação. Pela experiência profissional, ouvíamos reclamações dos pais e alunos com relação ao acesso à internet, a ausência de aparelho celular, a impossibilidade de estudar em suas casas devido ao barulho, além de dificuldades financeiras que vinham enfrentando. Neste artigo abordaremos as implicações desta realidade na vida escolar dos alunos.

Esta pesquisa foi realizada através de formulários eletrônicos, com perguntas abertas e fechadas, e enviados para grupos de redes sociais das escolas. Os sujeitos da pesquisa foram alunos do $9^{\circ}$ ano, pela frequência com que participam das aulas, com idades variando entre 15 a 17 anos, de três bairros de Maceió considerados vulneráveis: Tabuleiro dos Martins, Benedito Bentes e Cidade Universitária. Foram pesquisados 55 alunos estudantes da rede Municipal de ensino que foi a primeira a retomar o ensino remoto em 2020, ao completarem 1 ano nesta modalidade de ensino emergencial. Os dados foram analisados de forma descritiva e inferencial em gráficos gerados pelo próprio aplicativo para as perguntas fechadas, e pelas contagens de palavras, bem como seus contextos, nas perguntas abertas.

\section{A vulnerabilidade social nos bairros dos alunos}

Os problemas enfrentados pelos professores estão dentro e fora da escola, há uma massa de alunos e alunas que vivem na periferia do Brasil, bairros populosos com uma taxa de natalidade muito elevada. As adolescentes que estão neste grupo de vulnerabilidade engravidam muito cedo, até porque a desigualdade social no Brasil causa uma escassez em projetos e propostas para a educação sexual e acesso a métodos contraceptivos, além da falta de perspectivas de crianças e adolescentes que moram nas periferias (BOURDIEU, 2015).

A vulnerabilidade social é um conceito multifatorial que vários autores se debruçaram sobre ele. Na Política Nacional de Assistência Social - PNAS (BRASIL, 2004) aborda-se uma dimensão material que é a fragilidade devida à exposição de processos de exclusão social de

Revista Tópicos Educacionais, Pernambuco, v. 27, n. 01, p. 22-33, 2021. ISSN: 2448-0215. https://periodicos.ufpe.br/revistas/topicoseducacionais/index Dossiê "Conflitos, violências, bullying na escola: problemas da convivência potencializado pela pandemia?" DOI: 10.51359/2448-0215.2021.250234 
famílias que vivenciam contextos de pobreza, privação de direitos e, a dimensão relacional que é a fragilização de vínculos afetivos relacionados ao pertencimento social. Segundo Perona e Rocchi (2001, p. 4),

Vulnerabilidade não é o mesmo que pobreza, se bem que a inclui. Esta última faz referência a uma situação de carência efetiva e atual, mas a vulnerabilidade transcende esta condição, projetando no futuro a possibilidade de sofrer a partir de certas debilidades que se constatam no presente (tradução nossa).

Kaztman (1999) entende que a vulnerabilidade social é resultante da estrutura de oportunidades (mercado, sociedade e estado) e as capacidades dos territórios (condições habitacionais, transporte, saneamento), essas diferenças geram diversos graus de vulnerabilidade. Neste raciocínio, Lopes (2008, p. 357) enfatiza que, "nos processos de exclusão produzidos no mundo neoliberal, mais que controlar ou negar o acesso ao trabalho ou ao consumo, a sociedade capitalista controla e nega a própria condição de sujeiticidade do indivíduo".

Figueiredo e Noronha (2008, p. 131) definem a vulnerabilidade social como a ausência de "recursos materiais e simbólicos dos atores, sejam eles indivíduos ou grupos, e o acesso à estrutura de oportunidades sociais, econômicas, culturais que preveem do Estado, do mercado e da sociedade". Para o DIEESE (2007), a precariedade do trabalho, a fragilidade dos suportes das redes de apoio social e a falta de proteção social são fatores que dilatam a zona de vulnerabilidade social.

Além destas situações instaladas de vulnerabilidade social, temos as temporárias, como a pandemia do Coronavírus, que agravou o caos para estas famílias que já estavam em risco social.

Buscamos reunir algumas variáveis citadas pelos autores como indicativos de situação de vulnerabilidade social para apresentarmos a realidade dos bairros que os alunos pesquisados residem.

Quadro 1 - Condições sociais dos bairros pesquisados

\begin{tabular}{|c|c|c|c|c|c|c|}
\hline \multirow[b]{2}{*}{ BAIRRO } & \multirow[b]{2}{*}{$\begin{array}{c}\text { RENDA } \\
\text { FAMILIAR }\end{array}$} & \multirow[b]{2}{*}{ HABITANTES } & \multicolumn{2}{|c|}{$\begin{array}{l}\text { DESCUMPRIMENTO EM } \\
\text { EDUCAÇÃO* }\end{array}$} & \multirow[b]{2}{*}{$\begin{array}{l}\text { DESCUMPRIMENTO } \\
\text { EM SAÚDE** }\end{array}$} & \multirow[b]{2}{*}{$\begin{array}{l}\text { TRABALHO } \\
\text { INFANTIL } * * *^{*}\end{array}$} \\
\hline & & & $\begin{array}{l}\text { Abandono / } \\
\text { Desistência }\end{array}$ & $\begin{array}{l}\text { Negligência } \\
\text { da Família / } \\
\text { Responsáveis }\end{array}$ & & \\
\hline $\begin{array}{l}\text { BENEDITO } \\
\text { BENTES }\end{array}$ & 989,07 & 88.084 & $50 \%$ & $50 \%$ & 447 & $16 \%$ \\
\hline $\begin{array}{c}\text { CIDADE } \\
\text { UNIVERSITÁRIA }\end{array}$ & $1.348,56$ & 71.441 & $75 \%$ & $25 \%$ & 208 & $11 \%$ \\
\hline $\begin{array}{c}\text { TABULEIRO } \\
\text { DOS MARTINS }\end{array}$ & $1.441,90$ & 64.755 & $75 \%$ & $25 \%$ & 276 & $11 \%$ \\
\hline
\end{tabular}

Legenda: *Condições de descumprimento em Educação com relação as famílias; **quantidade de famílias em descumprimento da condicionante saúde; ***incidência de trabalho infantil.

Fonte: Plano Municipal de Assistência Social de Maceió, 2018-2021

Revista Tópicos Educacionais, Pernambuco, v. 27, n. 01, p. 22-33, 2021. ISSN: 2448-0215. https://periodicos.ufpe.br/revistas/topicoseducacionais/index Dossiê "Conflitos, violências, bullying na escola: problemas da convivência potencializado pela pandemia?" DOI: 10.51359/2448-0215.2021.250234 
Considerando que as famílias destes bairros possuem 2 ou mais membros, a renda mensal girar em torno de $\mathrm{R} \$ 1.200,00$, é um valor muito abaixo da renda per capta registrada para Alagoas por Alvarenga e Silveira (2021) de R \$ 796,00.

Os alunos se encontram nos bairros mais populosos da capital alagoana, e contam com uma alta taxa de abandono e negligência familiar de acordo com a SEMAS (2018). Existe um número expressivo de famílias ainda sem acompanhamento da saúde, e ressaltamos que essa população carece de alimentação básica em suas casas. A falta de acesso à saúde publica e as desestruturações das unidades básicas contribuem para o descumprimento do condicionante saúde.

Com a pandemia a esperança de eliminar a pobreza torna-se ameaçada, parece-nos que há uma grande preocupação com a retomada da economia por parte do governo, conforme a mídia vem noticiando, enquanto uma margem da população sofre com fome, seca, poucas oportunidades, e sem usufruir de seus direitos humanos básicos.

As recomendações de proteção e isolamento não são possíveis de se concretizar para quem vive em comunidades e periferias, o Estado é provocado a elaborar políticas públicas que possam subsidiar estas famílias com cestas básicas e kits de higiene doados periodicamente.

Essa realidade difícil se estende à Educação: os alunos sem estruturas em suas casas, sem equipamento adequado para assistirem aula, e sem conectividade adequada para acompanhar 4 horas diárias de aula online.

Para Piccoli, Lena e Gonçalves (2019, s.p.), outro agravante se soma a aspectos de vulnerabilidade social, a "escola aparece como justa e "neutra", intervindo muito pouco na vida dos alunos, mas, como as injustiças e desigualdades escolares seriam consequências das iniquidades sociais", a Escola acaba reproduzindo a exclusão social, e os alunos não encontram nela ajuda para saírem desta realidade (BOURDIEU; PASSERON, 1975).

\section{Os alunos em vulnerabilidade no ensino remoto}

A dificuldade no desenvolvimento dos conteúdos, o horário irregular, o não cumprimento da carga horária mínima de 4 h diárias de acordo com a Lei de Diretrizes e Bases (LDB) tem sido uma constante para as famílias pobres durante a pandemia. Alunos de 15 a 17 anos passam apenas $1 \mathrm{~h} 57$ minutos apenas estudando, enquanto nas famílias com poder aquisitivo

Revista Tópicos Educacionais, Pernambuco, v. 27, n. 01, p. 22-33, 2021. ISSN: 2448-0215. https://periodicos.ufpe.br/revistas/topicoseducacionais/index Dossiê "Conflitos, violências, bullying na escola: problemas da convivência potencializado pela pandemia?" DOI: 10.51359/2448-0215.2021.250234 
maior, segundo Neri (2020), tem um tempo 64\% maior de estudo por parte dos adolescentes, agravando assim a desigualdade.

Neri (2020) aponta que o não recebimento de material das respectivas redes, pode ser o vilão desta baixa acessibilidade dos alunos aos conteúdos escolares. Para os alunos de classe E, $25 \%$ não receberam nenhum material durante o último ano letivo remoto. Já os alunos das classes A, B, menos de 3\% não receberam. A desigualdade escolar que vinha caindo nos últimos 40 anos, agravou nesta pandemia.

Castro (2020) nos lembra que diversos outros aspectos desse momento pandêmico tem gerado consequência na escola. Segundo o autor,

Além dos problemas da escola a crise econômica trouxe consequências profundas para os alunos por causa de fatores externos à escola, tais como a ampliação das dificuldades econômicas das famílias que passam a conviver com desemprego, desalento, queda da renda, aumento da insegurança, entre outros fatores que prejudicam os alunos e os profissionais da educação e que acabam sendo levados para o ambiente escolar (p. 12).

A demanda pelo distanciamento social transcende a saúde, ela chega na Educação de forma muito intensa, mais de 40 milhões de estudantes tiveram que sair da modalidade presencial para a remota, conforme mostra Behar (2020). O período de isolamento físico e a distância presencial da Escola foram planejados, à priori, por alguns meses, mas nestas escolas pesquisadas já dura 1 ano. A tecnologia entrou para viabilizar uma espécie de normalidade, mas as crianças carentes não possuem acesso à tal forma de educação (MACHADO, 2020).

Com esse cenário novo a tecnologia é essencial e fez com que suavizasse os traumas entre a transição presencial e remota, porém como mostra Ximenes e Cassio (2020), a volta as aulas de forma remota promoveu uma desigualdade maior na educação para quem não tem acesso a estes equipamentos, quem é de baixa renda, de escolas públicas e até universidades (TORRES; ALVEZ; COSTA, 2020).

Segundo Marcelo, Ornellas e Bonfim (2020), durante o ensino remoto nas favelas o impacto é multidimensional, envolve questões financeiras, sanitárias, além da perda de entes queridos. Para os grupos de alunos em situação mais favorável, o acesso ao ensino remoto torna-se uma realidade, para os que estão nas periferias há uma defasagem que reportam à própria escola presencial até o hiato de um ano sem a presença da/na Escola.

Revista Tópicos Educacionais, Pernambuco, v. 27, n. 01, p. 22-33, 2021. ISSN: 2448-0215. https://periodicos.ufpe.br/revistas/topicoseducacionais/index Dossiê "Conflitos, violências, bullying na escola: problemas da convivência potencializado pela pandemia?" DOI: $10.51359 / 2448-0215.2021 .250234$ 


\section{Revista Tópicos Educacionais}

\section{Metodologia}

Esta pesquisa foi realizada no início do ano letivo de 2021 com alunos da rede municipal de três bairros situados na periferia de Maceió, ao completarem 1 ano de distanciamento presencial das Escolas.

Para coleta de dados utilizamos formulário eletrônico dividido em três seções. $\mathrm{Na}$ primeira, existia a explicação sobre a pesquisa e o termo de consentimento livre e esclarecido, só era possível para passar para a próxima seção, caso os alunos concordassem em participar da pesquisa. Na segunda seção, 8 perguntas de múltipla escolha, 1 pergunta aberta e 2 perguntas em escala likert, buscavam traçar o perfil dos alunos, entender o contexto familiar, a estrutura física de que dispunham em suas casas. Na terceira seção, 1 pergunta de múltipla escolha e 3 perguntas abertas foram utilizadas para compreender o processo de ensino e de aprendizagem durante o ensino remoto.

Nas perguntas de múltipla escolha pedimos a inserção do bairro, que tipo de modalidade o aluno prefere, se o aluno consegue estudar em casa, quantidade de pessoas que moram com ele na mesma casa, quantidade de quartos. As perguntas em escala likert trataram sobre a nota que o aluno daria para o desempenho dos professores, e que nota ele daria para seu desempenho no ensino remoto. As perguntas abertas versaram sobre o que o aluno mais sente falta do ensino presencial, a maior dificuldade no ensino remoto, além de outras perguntas para compreender o cotidiano deste aluno e sua família durante o tempo em que a Escola se transferiu para suas casas.

A análise de dados se deu de forma estatística através dos gráficos que o aplicativo gera automaticamente, e de inferências a partir das respostas às perguntas abertas com contagem de palavras mais evocadas, além de análise do contexto.

Um total de 55 alunos participaram da pesquisa de forma voluntária, os questionários foram enviados nos grupos de whatsapp dos alunos que estavam no $9^{\circ}$ ano das Escolas da parte alta de Maceió (onde se concentram os bairros mais populosos e com maior número de Zonas de Especial Interesse Social - ZEIS), junto com uma explicação sobre a finalidade da pesquisa. A escolha do $9^{\circ}$ ano se deve por ser a última etapa de ensino da rede municipal e concentrar os alunos com maior frequência no ensino remoto, de acordo com a experiência profissional dos pesquisadores.

Revista Tópicos Educacionais, Pernambuco, v. 27, n. 01, p. 22-33, 2021. ISSN: 2448-0215. https://periodicos.ufpe.br/revistas/topicoseducacionais/index Dossiê "Conflitos, violências, bullying na escola: problemas da convivência potencializado pela pandemia?" DOI: $10.51359 / 2448-0215.2021 .250234$ 
Revista Tópicos Educacionais

Revista do Programa de Pós-Graduação em Educação da Universidade Federal de Pernambuco (UFPE)

\section{Resultados e discussão}

As perguntas sobre as conjunturas familiares trataram sobre renda mensal, estrutura residencial e o compartilhamento de cômodos como uma forma de perceber as condições de estudo que estes alunos possuem em suas casas.

Quadro 2 - Conjunturas familiares

\begin{tabular}{|c|c|c|c|c|c|c|c|c|c|}
\hline \multirow{2}{*}{ BAIRRO } & \multirow{2}{*}{$\begin{array}{l}\text { RENDA } \\
\text { FAMILIAR }\end{array}$} & \multicolumn{4}{|c|}{ QUANTIDADE DE QUARTOS } & \multicolumn{4}{|c|}{$\begin{array}{c}\text { QUANTIDADE DE PESSOAS QUE RESIDEM } \\
\text { NA SUA CASA } \\
\end{array}$} \\
\hline & & 1 & 2 & 3 & 4 ou mais & 2 & 3 & 4 & 5 ou mais \\
\hline $\begin{array}{l}\text { BENEDITO } \\
\text { BENTES }\end{array}$ & \multirow{3}{*}{ Até 1045,00} & 3 & 12 & 1 & 0 & 0 & 1 & 2 & 13 \\
\hline $\begin{array}{c}\text { CIDADE } \\
\text { UNIVERSITÁRIA } \\
\end{array}$ & & 0 & 8 & 9 & 3 & 1 & 6 & 2 & 11 \\
\hline $\begin{array}{l}\text { TABULEIRO } \\
\text { DOS MARTINS }\end{array}$ & & 0 & 10 & 5 & 4 & 0 & 4 & 3 & 12 \\
\hline
\end{tabular}

Fonte: pesquisa realizada com os alunos

Destes dados observamos que o bairro do Benedito Bentes, além de ter maior vulnerabilidade social, também é o que possui menores áreas em suas residências e maior quantidade de pessoas dividindo os cômodos. Em geral, são 2 quartos para 5 ou mais pessoas, e a renda é a mesma para os três bairros pesquisados, menos de 1 salário mínimo para uma média de 5 pessoas, uma situação caótica se compararmos aos valores registrados por Alvarenga e Silveira (2021).

Ao serem questionados sobre a maior dificuldade encontrada por eles durante os estudos remotos, é possível perceber a desigualdade na Educação Brasileira apontada por Kaztman (1999), Piccoli et al (2019), Macedo et al (2020).

Gráfico 1 - Maior dificuldade apontada pelos alunos de zonas periféricas
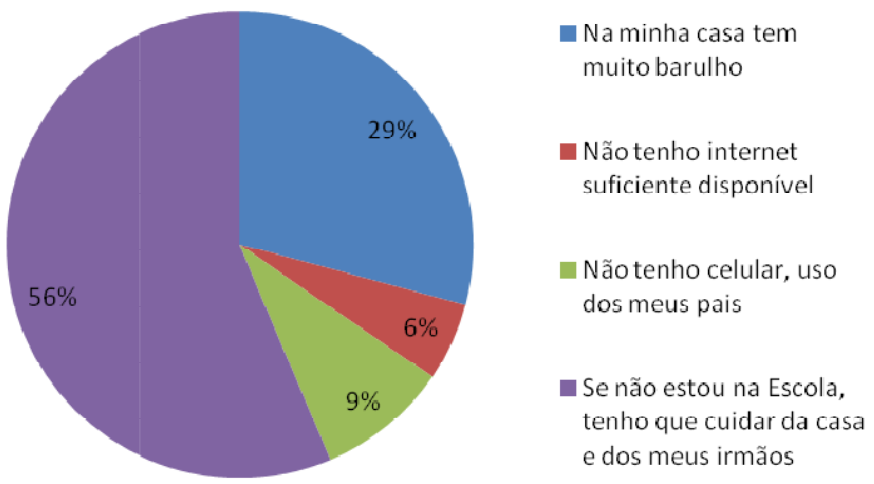

Revista Tópicos Educacionais, Pernambuco, v. 27, n. 01, p. 22-33, 2021. ISSN: 2448-0215.

https://periodicos.ufpe.br/revistas/topicoseducacionais/index

Dossiê "Conflitos, violências, bullying na escola: problemas da convivência potencializado pela pandemia?" DOI: 10.51359/2448-0215.2021.250234 
Alagoas é um Estado desigual, em renda, saneamento, bens, gênero, mas a desigualdade é extrema nas favelas. Famílias recolhem comidas nos lixões, ou comem sururu ${ }^{3}$ como a única opção alimentar, crianças apresentam sinais de desnutrição. Milhares de pessoas vivem em condições de miséria, sem acesso a creche por conta da pandemia. Sem investimento do governo em leitura, em conexão, sem redes de contato, sem comida, num processo amplo que vem desde 1850 (FERREIRA, 2021). E neste meio estão as escolas tentando se fazerem presentes nestas casas de forma remota.

Famílias numerosas que precisam dividir os trabalhos domésticos com os filhos e não percebem na escola uma forma de ascensão social. O conceito de desigualdade no contexto educacional se refere a estas oportunidades que afetam estes alunos na medida em que não dá aos mesmos indivíduos, da rede pública ou privada, as mesmas condições.

A educação que poderia equalizar as chances reproduz as desigualdades ao invés de eliminá-las (BOURDIEU; PASSERON, 1975). Quando pensamos nos grupos vulneráveis na educação, temos que considerar o território que habitam, as condições da família, a violência no espaço doméstico, o capital cultural dos pais.

Segundo a UNICEF (2021), o Brasil pode regredir duas décadas na Educação por causa dos efeitos da pandemia. Com escolas fechadas, o número de crianças e adolescentes fora da escola saltou de 1,3 milhões para 4 milhões, e mesmo que retorne ao ensino presencial há o risco destes alunos não voltarem às Escolas por terem optado pelo trabalho infantil.

Ao serem perguntados o que sentem mais falta quando pensam em aulas presenciais, $76 \%$ dos alunos afirmaram que precisam estar em outros ambientes, precisam estar em contato com seus amigos, ou seja, nossos alunos estão sobrecarregados com os afazeres domésticos, sem perceber a importância que a escola tem na construção de seu futuro de forma mais promissora, mas vendo nela a única condição de sair momentaneamente daquela situação de opressão.

Gráfico 2 - O que os alunos mais sentem falta quando pensam nas aulas presenciais

\footnotetext{
${ }^{3}$ Marisco que cresce envolto a uma concha, encontrado nos mangues alagoanos, com alto teor nutricional. Revista Tópicos Educacionais, Pernambuco, v. 27, n. 01, p. 22-33, 2021. ISSN: 2448-0215. https://periodicos.ufpe.br/revistas/topicoseducacionais/index Dossiê "Conflitos, violências, bullying na escola: problemas da convivência potencializado pela pandemia?" DOI: $10.51359 / 2448-0215.2021 .250234$
} 
Revista Tópicos Educacionais

Revista do Programa de Pós-Graduação em Educação da Universidade Federal de Pernambuco (UFPE)
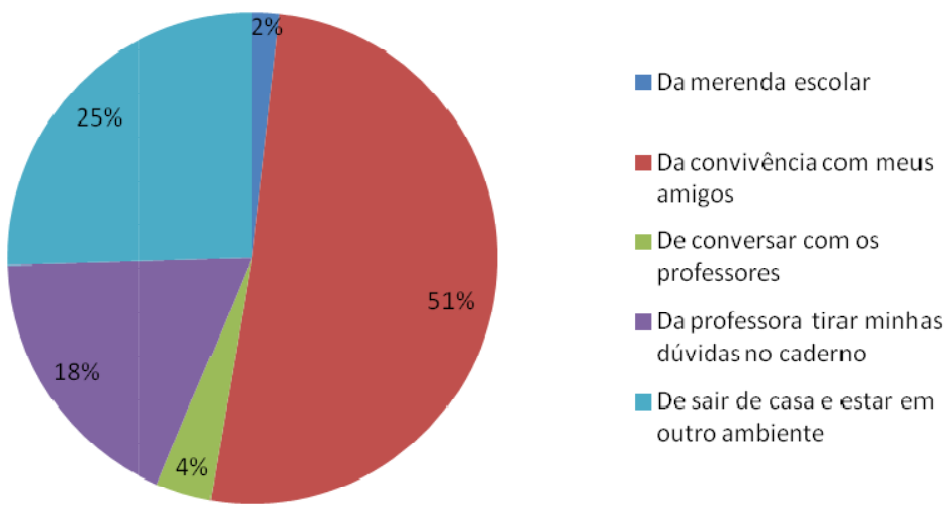

Fonte: pesquisa realizada com os alunos

A complexidade que envolve a vulnerabilidade social numa cidade como Maceió, em que a Educação de qualidade já era um desafio e agora é inacessível, exige políticas educacionais voltadas para a erradicação da fome, a saúde, a habitação, para a conectividade. Políticas em que as metas são prioridades podem ser importantes para o governo prestar conta no cenário mundial, mas podem não revelar situações extremas como as vivenciadas pelos nossos alunos.

Ao serem perguntados se mesmo com todos os problemas elencados por eles, se conseguiam estudar em casa, obtivemos a seguinte resultado:

Gráfico 3 - Você consegue estudar em casa?

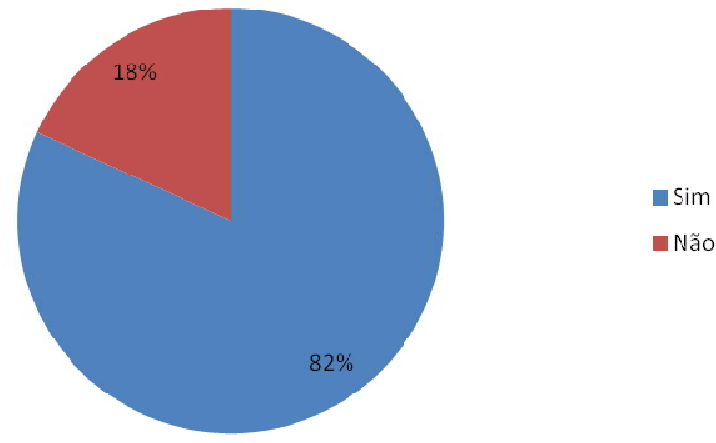

Fonte: pesquisa realizada com os alunos

É possível observar um todo contraditório em que se organizam os discursos dos alunos, mesmo tendo que cuidar da casa no horário das aulas, sem internet, com barulho provocado pelo número de habitantes na casa e com poucos cômodos, os alunos colocam que conseguem estudar em casa.

Revista Tópicos Educacionais, Pernambuco, v. 27, n. 01, p. 22-33, 2021. ISSN: 2448-0215.

https://periodicos.ufpe.br/revistas/topicoseducacionais/index

Dossiê "Conflitos, violências, bullying na escola: problemas da convivência potencializado pela pandemia?" DOI: $10.51359 / 2448-0215.2021 .250234$ 
Em todos os espaços sociais existe uma configuração que determina a atuação das pessoas como ela deve se portar diante de um problema, os alunos se acomodaram a falar que estava tudo bem porque imersos em uma crise sanitária e em meio a tantos problemas que circundam a sua casa, eles acabam sendo compelidos a adotar uma postura de aceitação daquela realidade. A isso, Bourdieu (1989) dava o nome de violência simbólica.

\section{A violência simbólica na ausência de políticas educacionais}

Para Bourdieu (1989), estudar a sociedade é uma forma de combater as desigualdades. Neste sentido, o autor visa desnudar a realidade social, as sociedades possuem um poder simbólico, um acúmulo onde uns indivíduos buscam persuadir outros indivíduos.

Ao mencionar a violência e seus tipos, Bourdieu (1989) não se restringe a violência física, mas a uma violência mais sutil, em que o poder transpõe as instituições. O estado é a instituição que detém o monopólio da violência física, mas o capital não é meramente cultural. Os seres humanos possuem o capital econômico, social, cultural, e simbólico, e é pelo capital simbólico que as instituições e indivíduos tentam ludibriar grupos fragilizados.

Segundo Bourdieu (1989), a violência simbólica acontece quando existe desequilíbrio entre a honra, o prestígio e o reconhecimento dos grupos na sociedade. No capital simbólico carregamos experiências particulares, significados, e mesmo nos espaços que não percebemos que há violência, existe violência, e está naturalizada.

A classe oprimida não percebe que está fazendo o jogo dos dominadores, e não se revolta contra aquela situação, é como um

Poder quase mágico que permite obter o equivalente daquilo que é obtido pela força (física ou econômica), graças ao efeito específico de mobilização, só se exerce se for reconhecido, quer dizer, ignorado como arbitrário. (BOURDIEU, 1989, p.14)

É um poder baseado na conveniência, numa violência suave mediada pela comunicação, que se vale do desconhecimento do outro devido a ausência de discernimento, tornase uma verdade incorporada ao discurso do oprimido sem perceber que está sendo manipulado,

A força simbólica é uma forma de poder que se exerce sobre os corpos, diretamente, e como que por magia, sem qualquer coação física; mas essa magia só atua com o apoio de predisposições colocadas, como molas propulsoras, na zona mais profunda dos corpos. (BOURDIEU, 1989, p. 50).

Revista Tópicos Educacionais, Pernambuco, v. 27, n. 01, p. 22-33, 2021. ISSN: 2448-0215. https://periodicos.ufpe.br/revistas/topicoseducacionais/index Dossiê "Conflitos, violências, bullying na escola: problemas da convivência potencializado pela pandemia?" DOI: $10.51359 / 2448-0215.2021 .250234$ 
Um governo que não se importa com as carências sociais de um grupo, que não luta para mitigar os efeitos de uma pandemia, pode tentar esconder as verdadeiras relações de forças em prol de um elemento que para os vulneráveis está ocultado.

\section{Considerações}

A vulnerabilidade social nos bairros cujos alunos desta pesquisa residem foi agravada durante a pandemia, além da fome e desemprego, a falta de conectividade fez com que os alunos se distanciassem por completo da Escola. O colapso social se refletiu para famílias que tiveram que buscar sustento de alguma forma e deixaram seus filhos em casa para serem cuidados por outras crianças.

O tempo de estarem em sala de aula, foi redirecionado para cuidar dos afazeres domésticos, os alunos apontaram que mesmo com o acesso a internet para assistirem as aulas, não era possível estar presentes porque eles precisavam trabalhar.

A primeira grande crise global escancarou as desigualdades sociais e num País que as políticas públicas para a educação sempre foram escassas, com essa pandemia, tornaram-se inexistentes. A extrema vulnerabilidade maquiada com alguns auxílios do governo e o discurso de que não se podia fazer mais nada, fragilizou ainda mais uma parcela da população que sem forças para lutar, sobrevive sob um silêncio ensurdecedor dos governantes, caracterizando uma violência simbólica uma produção contínua de crenças de que o governo já está fazendo a sua parte e que a população oprimida deve agradecer.

\section{Referências}

ALVARENGA, D.; SILVEIRA, D. Renda domiciliar per capita caiu em 2020, para R\$ 1.380. Jornal G1, São Paulo, 26, fev, 2021. Disponível em: https://g1.globo.com/economia/noticia/2021/02/26/renda-domiciliar-per-capita-foi-de-r-1380-em2020-diz-ibge.ghtml

BEHAR, P. A. O Ensino Remoto Emergencial e a Educação a Distância, 2020. Disponível em: https://www.ufrgs.br/jornal/o-ensino-remoto-emergencial-e-a-educacao-a-distancia/. Acesso em: 12 Jan. 2021.

BOURDIEU, P. A dominação masculina. Trad. Maria Helene Kühner. 13 ed. Rio de Janeiro: Bertrand Brasil, 2015.

, P. O poder simbólico. Rio de Janeiro: Bertrand, 1989.

Revista Tópicos Educacionais, Pernambuco, v. 27, n. 01, p. 22-33, 2021. ISSN: 2448-0215. https://periodicos.ufpe.br/revistas/topicoseducacionais/index Dossiê "Conflitos, violências, bullying na escola: problemas da convivência potencializado pela pandemia?" DOI: $10.51359 / 2448-0215.2021 .250234$ 
BOURDIEU, P.; PASSERON, J. A reprodução: elementos para uma teoria do sistema de ensino. Rio de Janeiro: Francisco Alves, 1975.

BRASIL. Ministério do Desenvolvimento Social e Combate à Fome. Conselho Nacional de Assistência Social. Política Nacional de Assistência Social. Brasília: Ministério do Desenvolvimento Social e Combate à Fome, 2004.

CASTRO, J. A. Proteção social em tempos de Covid-19. Saúde em debate, São Paulo, v. 4, n. 12, p. 1-16, mar., 2020.

DIEESE. Aspectos conceituais da vulnerabilidade social. Projeto de qualificação social para atuação de sujeitos ou grupos sociais na negociação coletiva e na gestão de políticas públicas. Convênio MTE/SPPE/CODEFAT - n. 075/2005 e Primeiro Termo Aditivo, 2007.

FERREIRA, A. Famílias sem renda e desempregadas estão com as despensas, geladeiras e panelas vazias na pandemia em Alagoas. Jornal Gazeta de Alagoas, Maceió, 17, abr., 2021.

FIGUEIREDO, I.; NORONHA, R. L. A vulnerabilidade como impeditiva/ restritiva do desfrute de direitos. Revista de Direitos e Garantias Fundamentais, Vitória, v. 4, p. 129-146, 2008.

LOPES, J. R. Processos sociais de exclusão e políticas públicas de enfrentamento da pobreza. Caderno CRH, Salvador, v. 21, n. 53, p. 349-363, 2008.

MACEDO, Y.M; ORNELLAS, J.L.; BONFIM, H.F. COVID 19 nas Favelas e Periferias Brasileiras. Boletim de Conjuntura, Boa Vista, v. 2, n. 4, 2020.

MACHADO, P. L. P. Educação em tempos de pandemia: O ensinar através de tecnologias e mídias digitais. Revista Científica Multidisciplinar Núcleo do Conhecimento. São Paulo, v. 8, n. 6, p. 58-68, jun, 2020.

NERI, M. Pandemia agravou desigualdade na educação, aponta pesquisa; falta de recursos é motivo. Cultura UOL, São Paulo, 22, out, 2020. Disponível em: https://cultura.uol.com.br/noticias/13593 pandemia-agravou-desigualdade-na-educacao-apontapesquisa-falta-de-recursos-e-motivo.html Acesso em: 13 dez 2020.

PICCOLI, L. M.; LENA, M. S.; GONÇALVES, T. R. VIOLÊNCIA E SOFRIMENTO SOCIAL NO CONTEXTO ESCOLAR: UM ESTUDO DE CASO EM PORTO ALEGRE, RS, SAÚDE SOC., V. 28, N. 4, P. 1-12, 9, DEZ, 2019.

TORRES, A. C. M.; ALVES, L. R. G.; COSTA, A. C. N. Educação e Saúde: reflexões sobre o contexto universitário em tempos de COVID-19. Scielo em Perspectiva, 2020. Disponível em: https://preprints.scielo.org/index.php/scielo/preprint/view/640/885. Acesso em: 13 Dez. 2020.

\section{UNICEF. Impactos Primários e Secundários da COVID-19 em Crianças e Adolescentes. Relatório de análise $2^{\mathrm{a}}$ Rodada UNICEF, 2021. Disponível em:}

Revista Tópicos Educacionais, Pernambuco, v. 27, n. 01, p. 22-33, 2021. ISSN: 2448-0215. https://periodicos.ufpe.br/revistas/topicoseducacionais/index Dossiê "Conflitos, violências, bullying na escola: problemas da convivência potencializado pela pandemia?" DOI: 10.51359/2448-0215.2021.250234 
Revista Tópicos Educacionais

Revista do Programa de Pós-Graduação em Educação

da Universidade Federal de Pernambuco (UFPE)

https://www.unicef.org/brazil/relatorios/impactos-primarios-e-secundarios-da-covid-19-emcriancas-e-adolescentes-segunda-rodada Acesso em: 18 abr. 2021.

XIMENES, S; CÁSSIO, F. Coronavírus e a "Volta às Aulas". Le Monde Diplomatique, São Paulo, 31, mar., 2020. Disponível em: https://diplomatique.org.br/coronavirus-e-a-volta-as-aulas/. Acesso em: $12 \mathrm{dez} 2020$.

Recebido em abril de 2021.

Aprovado em junho de 2021.

Revista Tópicos Educacionais, Pernambuco, v. 27, n. 01, p. 22-33, 2021. ISSN: 2448-0215.

https://periodicos.ufpe.br/revistas/topicoseducacionais/index

Dossiê "Conflitos, violências, bullying na escola: problemas da convivência potencializado pela pandemia?" DOI: $10.51359 / 2448-0215.2021 .250234$ 